\title{
Rapid Detection of Salmonella spp. in Animal Origin Foods by In-House Developed Loop-Mediated Isothermal Amplification (LAMP) Assay
}

\author{
V.R. Masoji, R.J. Zende, R.D. Suryawanshi, V.M. Vaidya, R.N. Waghamare, \\ D.P. Kshirsagar*, R.P. Todankar and A.H. Shirke \\ Department of Veterinary Public Health and Epidemiology, \\ Bombay Veterinary College, Parel, Mumbai, India \\ *Corresponding author
}

\begin{tabular}{|c|c|}
\hline & B S T R A T \\
\hline Keyw & \multirow{9}{*}{$\begin{array}{l}\text { Salmonellosis is one of the most common causal food borne disease in India. An in-house } \\
\text { loop-mediated isothermal amplification (LAMP) reaction was established and evaluated } \\
\text { for sensitivity and specificity in detecting the presence of Salmonella spp. isolates in foods } \\
\text { of animal origin from Mumbai, India. The aim of this study was to develop in-house } \\
\text { LAMP for simple and inexpensive detection of Salmonella spp. in animal origin foods } \\
\text { using specifically designed primers targeting invA gene contains sequences unique to this } \\
\text { genus. The reaction was optimized using genomic DNA of S. typhimurium (MTCC } 3224 \text { ) } \\
\text { as the template. The assay was conducted in a water bath for } 1 \mathrm{~h} \text { at } 65^{\circ} \mathrm{C} \text {. The results were } \\
\text { visualized after addition of SYBR Green } ® \text { fluorescent dye. The test was further evaluated } \\
\text { on } 59 \text { serotyped Salmonella field isolates to ensure its reliability and usefulness. The } \\
\text { results were compared with those obtained by gold standard culture method and } \\
\text { Polymerase Chain Reaction (PCR). This method was highly specific and } 10 \text { times more } \\
\text { sensitive in detecting Salmonella spp. compared to the optimized conventional polymerase } \\
\text { chain reaction (PCR) method. This simple method may be applied on field diagnostic } \\
\text { laboratories without access to expensive equipment. }\end{array}$} \\
\hline ed & \\
\hline & \\
\hline (LAMP), & \\
\hline & \\
\hline & \\
\hline & \\
\hline Article In & \\
\hline & \\
\hline
\end{tabular}

\section{Introduction}

Salmonella is a gram-negative bacterium belonging to family Enterobacteriaceae and is an important cause of food-borne bacterial infections in both developed and developing countries (European Food Safety Authority, 2007). A variety of foods have been implicated as vehicles transmitting salmonellosis to humans, including poultry, beef, pork, eggs, milk, cheese, fish, shellfish, fresh fruit and juice, and vegetables (Kshirsagar et al., 2014). Salmonella was the second most common aetiology, causing $1,449(18 \%)$ of the 7,998 outbreaks with a confirmed or suspected single aetiology and 39,126 (19\%) illnesses in the United States (Gould et al., 2013).

At present, standard methods for Salmonella detection and identification include mainly bacteria isolation and biochemical identification. Culture-based methods are reliable but laboratory-intensive, timeconsuming and demanding several days for definitive results, while cross biochemical reaction can occur between different species under Enterobacteriaceae (Yang et al., 2010; 
Kokkinos et al., 2014). For public health and the food industry rapid, sensitive and specific method to detect Salmonella in foods is required (Ueda and Kuwabara, 2009). A number of nucleic acid-based molecular methods have been successfully used to detect Salmonella spp. (Zhuang et al., 2014) and the requirement for expensive equipment's and reagents renders them unfavorable for widescale use, particularly under field conditions (Kokkinos et al., 2014).

Loop-mediated Isothermal Amplification (LAMP) was developed by Notomi et al., (2000), which can be used to detect foodborne pathogens. It amplifies target gene under isothermal conditions with high efficiency, specificity and rapidity (HaraKudo et al., 2005). This method relies on the auto-cycling strand displacement nature of $B s t$ DNA polymerase with high strand displacement activity and a set of two specially designed inner and two outer primers. This novel method can amplify a few copies of DNA to $10^{9}$ copies in less than an hour under isothermal conditions $\left(60-65^{\circ} \mathrm{C}\right)$ (Zhuang et al., 2014). The expensive equipment like thermocycler is not necessary to give a high level of precision, equivalent or greater, when compared to PCR. The LAMP technique would be most suited for out-oflaboratory detection activities and would also be most suited for poorly equipped laboratories or testing institutions (Boehme et al., 2007).

The invA gene of Salmonella contains sequences unique to this genus and has been proved as a suitable PCR target, with potential diagnostic applications (Rahn et al., 1992). In an International research project for the validation and standardization of PCR for the detection of five major food-borne pathogens including Salmonella, the most selective primer set which targets the location at $139-141$ on genomic sequence of
Salmonella, signified the invA gene. In present research work, we developed and applied a specific in-house LAMP method for detecting Salmonella spp. from foods of animal origin and the results were compared with gold standard culture methods and PCR assay.

\section{Materials and Methods}

\section{Isolation of Salmonella spp. from animal origin foods}

A total of 490 different animal origin foods comprising of viz. meat (50 muttons, 150 chicken, 80 buffalo meat and 60 pork), and 50 each of fish, eggs and milk were collected from various retail shops from different regions of Mumbai City. These samples were further processed for isolation of Salmonella spp. following standard technique as per IS 5887 (Part 3): 1999. Out of 490 animal origin food samples, 59 (12.04\%) samples showed presence of Salmonella as shown in Table 1.

All of these isolates were further characterized by biochemical tests and the results were interpreted and validated as per Bacteriological Analytical Manual for Salmonella (2007). Further, these 59 positive Salmonella isolates were then subjected for detection by standardized conventional Polymerase Chain Reaction (PCR) and Loopmediated Isothermal Amplification (LAMP) methods.

\section{Bacterial strains and DNA extraction}

Five reference strains including reference strain of S. typhimurium (MTCC 3224) and 04 other non-Salmonella species viz. E. coli. (MTCC-443), Pseudomonas aeruginosa (MTCC-4673), Shigella flexneri (MTCC1457) and Staphylococcus aureus (MTCC 3160) were used in this study procured from MTCC, Institute of Microbial Technology, 
Chandigarh, India. Additionally, 59 field isolates of Salmonella spp. isolated and serotyped at National Salmonella Centre (Veterinary), Division of Bacteriology and Mycology, Indian Veterinary Research Institute (IVRI), Izatnagar, Bareilly, India were included in the study.

Genomic DNA of Salmonella spp. was extracted as per the protocol of Rawool et al., (2007) with slight modifications. A colony of Salmonella isolate on Nutrient agar was picked and mixed with $1000 \mu$ l of NSS in centrifuge tube. It was then centrifuged at $10,000 \mathrm{rpm}$ for $10 \mathrm{~min}$. After centrifugation, the pellet formed was dissolved in $100 \mu \mathrm{l}$ of nuclease free water (NFW), vortexed and further boiled at $100^{\circ} \mathrm{C}$ for $10 \mathrm{~min}$. The centrifuge tube was subjected to rapid cooling in ice which was followed by centrifugation at $10,000 \mathrm{rpm}$ for $10 \mathrm{~min}$. Then, the upper aqueous phase which contained DNA was transferred to sterile micro-centrifuge tube. These extracted DNAs were further used for amplification. Until use these were stored at freezing temperature $\left(-20^{\circ}\right.$ to $\left.-80^{\circ} \mathrm{C}\right)$ in sterile micro-centrifuge tube.

\section{LAMP primer design}

The primers were designed using online LAMP primer designing software Primer Explorer V4 program by Eiken Chemicals Co. Ltd., Japan. The gene sequences were aligned and analysed by the online software program (http://primerexplorer.jp/elamp4.0.0/index. html) to design the following Salmonellaspecific primers: F3 (forward outer primer), B3 (backward outer primer), FIP (forward inner primer) and BIP (backward inner primer). The outer primers consisted of F3 and B3, while the inner primers consisted of FIP and BIP and were commercially synthesized by Integrated DNA Technologies (IDT) obtained from Sigma Aldrich, Bangalore, India. The primers used in PCR for the specific detection of Salmonella spp. were previously described by (Rahn et al., 1992). The sequences of the primers are summarized in table 2.

\section{Optimization of LAMP assay}

To optimize LAMP conditions, the test was carried at different temperatures $\left(60^{\circ} \mathrm{C}, 62^{\circ} \mathrm{C}\right.$, $64^{\circ} \mathrm{C}, 66^{\circ} \mathrm{C}, 68^{\circ} \mathrm{C}$, and $\left.70^{\circ} \mathrm{C}\right)$ and also at different time periods $(40,50,60$, and 70 min). LAMP reaction mixture was optimized using different concentrations of inner primers, outer primers, MgSO4, and dNTPs. In all reactions, eight units of Bst DNA polymerase, $1 \mathrm{M}$ betaine and $2 \mu \mathrm{l}$ of DNA template were used. The LAMP product was examined by direct observation of the reaction tubes. The insoluble white precipitate was noticed in the reaction tube due to formation of magnesium pyrophosphate, which had direct correlation with amplification. The LAMP products were also examined by submarine gel electrophoresis on $2 \%$ agarose gel with prestained ethidium bromide $(5 \mathrm{mg} / \mathrm{mL})$ in $0.5 \mathrm{X}$ tris-EDTA electrophoresis buffer. One microliter of SYBR green dye in 1:100 dilutions was used as colouring agent to the LAMP product and observed under day light.

\section{Optimization of invA PCR}

The PCR procedure to screen isolates for invA gene (Salmonella genus specific) was standardized as described by Rahn et al., (1992) with some modifications. The amplification was performed in total volume of $25 \mu$ containing $1.5 \mathrm{mM} \mathrm{MgCl} 2,0.2 \mathrm{mM}$ dNTPs mix, 10 pmol each of forward and reverse primers, $5 \mu \mathrm{l}$ of template DNA and 1 unit Taq DNA polymerase. The cycling condition comprised an initial denaturation at $95^{\circ} \mathrm{C}$ for $5 \mathrm{~min}$, followed by 30 cycles each of denaturation at $95^{\circ} \mathrm{C}$ for $1 \mathrm{~min}$, primer 
annealing at $65^{\circ} \mathrm{C}$ for $1 \mathrm{~min}$, elongation at $72^{\circ} \mathrm{C}$ for $1 \mathrm{~min}$ and finally a single extension step at $72^{\circ} \mathrm{C}$ for $10 \mathrm{~min}$. Amplified PCR product ( $284 \mathrm{bp}$ ) was analyzed by agarose gel electrophoresis on $1.5 \%$ agarose gel.

\section{Sensitivity of the LAMP assay}

For sensitivity (detection limit) of LAMP assay was evaluated using 200, 150,100 and $50 \mathrm{ng} / \mu \mathrm{l}$ DNA. The DNA was further diluted serially 10 folds to $2,1.5,1$ and $0.5 \mathrm{pg} /$ tube, respectively. $2 \mu \mathrm{l}$ of DNA from each dilution was taken to perform Salmonella specific LAMP, making the resultant minimum concentrations of 4, 3, 2 and 1pg/tube DNA, respectively. The reaction was performed at $65^{\circ} \mathrm{C}$ for $60 \mathrm{~min}$, and the results of this assay were compared with conventional PCR.

\section{Specificity of LAMP assay}

The specificity of LAMP assay was tested using standard Salmonella DNA template and 4 other templates from non-Salmonella strain. The DNA templates were prepared as described previously. The specificity of Salmonella specific LAMP was performed by testing it with four other bacterial species viz. E. coli, Pseudomonas aeruginosa, Shigella flexneri and Staphylococcus aureus. The reaction was performed at $65^{\circ} \mathrm{C}$ for $60 \mathrm{~min}$ and the results of this assay were compared with conventional PCR.

\section{Results and Discussion}

\section{LAMP conditions}

In order to determine the optimal conditions of LAMP, $S$. typhimurium reference strain (MTCC 3224) was used as the target template. LAMP assays were incubated under isothermal condition between 60 and $70^{\circ} \mathrm{C}$. The presence of significant visual turbidity and fluorescence on addition of SYBR green dye was observed at $65.0^{\circ} \mathrm{C}$ (Figures $1 \mathrm{~A} \&$ B). The optimal LAMP duration time was 60 min longer incubation up to $105 \mathrm{~min}$ had no influence on the final results. Therefore, the final LAMP condition for all strains was $65^{\circ} \mathrm{C}$ for $60 \mathrm{~min}$ then $80^{\circ} \mathrm{C}$ for $2 \mathrm{~min}$ to deactivate the polymerase. After completion of LAMP reaction, amplified DNA were analyzed on $2 \%$ of agarose gel by electrophoresis at $90 \mathrm{~V}$ for $45 \mathrm{~min}$. A 100bp DNA ladder was also loaded along with LAMP products and subsequently observed under U.V. Transilluminator of gel documentation system which exhibited specific ladder like pattern in case of DNA amplification (Figure 1C). The PCR was standardized for invA gene (284 bp) using reference strain (Figure 1D).

\section{Determination of detection limits (sensitivity) and specificity of LAMP}

\section{Sensitivity of LAMP}

The sensitivity (detection limit) of LAMP assay for Salmonella spp. was evaluated using 200, 150, 100 and $50 \mathrm{ng} / \mu \mathrm{l}$ DNA. This DNA was diluted serially 10 folds to $2,1.5,1$ and $0.5 \mathrm{pg} /$ tube, respectively and $2 \mu 1$ of DNA from each dilution was taken as a template to perform Salmonella specific LAMP, making the resultant minimum concentrations of 4,3 , 2 and $1 \mathrm{pg} /$ tube DNA, respectively. The amplification was carried out at $65^{\circ} \mathrm{C}$ for 60 min. and reaction was terminated at $80^{\circ} \mathrm{C}$ for 2 min. The study showed that LAMP could detect up to $4 \mathrm{ng} /$ tube concentration of DNA but further failed to detect 400pg/tube concentration of DNA (Figures 2 A \& B) Thus, the LAMP could able to detect the Salmonella spp. up to $4 \mathrm{ng} /$ tube concentration of DNA.

Similar protocol of DNA dilution was adopted for evaluating sensitivity (detection limit) of conventional PCR assay. However, conventional PCR could be able to detect the 
DNA up to $40 \mathrm{ng} /$ tube of DNA, failing to detect any further dilutions. Thus, conventional PCR could able to detect the Salmonella spp. up to 40ng/tube concentration of DNA.

The sensitivity (detection limit) of the LAMP assay was noted to be 10 fold greater than that of conventional PCR as LAMP could detect 4 ng/tube of Salmonella spp. DNA concentration, whereas, conventional PCR could able to detect 40ng/tube of concentration of Salmonella spp. DNA (Figure 2C).

\section{Specificity of LAMP}

In the present study, the specificity of LAMP assay was tested using standard Salmonella spp. DNA template and 4 other templates from non-Salmonella strains viz. $E$ coli, Pseudomonas aeruginosa, Shigella flexneri and Staphylococcus aureus. The LAMP was carried out as per the standard protocol at $65^{\circ} \mathrm{C}$ for $60 \mathrm{~min}$ in water bath. It was found that the LAMP assay successfully amplified Salmonella spp. DNA only, while it did not amplify any non-Salmonella organisms. Similarly, the PCR detected Salmonella spp. successfully and did not give any positive result with non-Salmonella strains (Figures 3A and B). Thus, the specificity of both LAMP and conventional PCR was found to be $100 \%$.

\section{Analysis of field samples}

Out of 490 various animal origin food samples, 59 (12.04\%) showed presence of Salmonella spp by cultural isolation followed by serotyping. Amongst 50 muttons, 150 chicken, 80 buffalo meat, 60 pork, and 50 each of fish, eggs and milk, the Salmonella isolates recovered were 5, 24, 16, 9, 3, 0 and 2 , respectively. Of the 59 Salmonella isolates 22 (37.28\%) belonged to S. Dublin, 13 (22.03\%) S. typhimurium and $12(20.33 \%)$ isolates each belonged to $S$. enteritidis and Other Salmonella spp. respectively as shown in Table 3.

After subjecting all the 59 positive Salmonella isolates to LAMP, it was observed that all the Salmonella isolates positive by cultural methods were detected positive by (100\%) using LAMP technique. However, on screening by conventional PCR, it was observed that PCR was able to detect 58 (98.30\%) positive Salmonella isolates. The only negative sample observed by PCR was the Salmonella spp. isolated from fish.

Table.1 Details of samples positive for Salmonella spp

\begin{tabular}{|c|c|c|c|c|}
\hline $\begin{array}{c}\text { Sr. } \\
\text { No. }\end{array}$ & $\begin{array}{c}\text { Type of food } \\
\text { sample }\end{array}$ & $\begin{array}{c}\text { Number of samples } \\
\text { examined }\end{array}$ & $\begin{array}{c}\text { Number of Salmonella } \\
\text { isolates recovered }\end{array}$ & $\begin{array}{c}\text { Prevalence } \\
(\mathbf{\%})\end{array}$ \\
\hline 1. & Mutton & 50 & 05 & 10 \\
\hline 2. & Chicken & 150 & 24 & 16 \\
\hline 3. & Buffalo meat & 80 & 16 & 20 \\
\hline 4. & Pork & 60 & 09 & 15 \\
\hline 5. & Fish & 50 & 03 & 06 \\
\hline 6. & Eggs & 50 & 00 & - \\
\hline 7. & Milk & 50 & 02 & 04 \\
\hline & Total & $\mathbf{4 9 0}$ & $\mathbf{5 9}$ & $\mathbf{1 2 . 0 4}$ \\
\hline
\end{tabular}


Table.2 Oligonucleotide sequences of LAMP primers used in this study

\begin{tabular}{|c|c|c|c|}
\hline $\begin{array}{l}\text { Sr. } \\
\text { No. }\end{array}$ & $\begin{array}{c}\text { Target } \\
\text { gene }\end{array}$ & Primer & Sequence (5'-3') \\
\hline 1. & $\operatorname{inv} \mathrm{A}$ & $\begin{array}{l}\text { LAMP Primers } \\
\text { F3: Forward outer primer } \\
\text { B3: Backward outer primer } \\
\text { FIP: Forward inner primer } \\
\text { (F1c-F2) } \\
\text { BIP: Backward inner } \\
\text { primer (B1c-B2) } \\
\text { PCR Primers }\end{array}$ & $\begin{array}{l}\text { F3: GAA CGT GTC GCG GAA GTC } \\
\text { B3: CGG CAA TAG CGT CAC CTT } \\
\text { FIP: GCG CGG CAT CCG CAT CAA TAT CTG } \\
\text { GAT GGT ATG CCC GG } \\
\text { BIP: GAA CGG CGA AGC GTA CTG GAC } \\
\text { ATC GCA CCG TCA AAG GAA } \\
\text { F: GTGAAATTATCGCCACGTTCGGGCAA } \\
\text { R: TCATCGCACCGTCAAAGGAACC }\end{array}$ \\
\hline
\end{tabular}

Table.3 Results of field samples by culture, PCR and LAMP

\begin{tabular}{|c|l|c|c|c|l|}
\hline \multirow{2}{*}{ Sr. no } & \multirow{2}{*}{$\begin{array}{c}\text { Source of } \\
\text { sample }\end{array}$} & \multicolumn{3}{|c|}{ invA Positive } & \multicolumn{2}{c|}{ Serotypes } \\
\cline { 3 - 6 } & Cultural & PCR & LAMP & \multicolumn{1}{|c|}{} \\
\hline 1 & Mutton & 05 & 05 & 05 & S. Enteritidis, S. Dublin, Other Salmonella \\
\hline 2 & Chicken & 24 & 24 & 24 & $\begin{array}{l}\text { S. typhimurium, S. Enteritidis, S. Dublin, } \\
\text { Other Salmonella }\end{array}$ \\
\hline 3 & Buffalo meat & 16 & 16 & 16 & S. Dublin, Other Salmonella \\
\hline 4 & Pork & 09 & 09 & 09 & S. Dublin, S. typhimurium, S. Enteritidis \\
\hline 5 & Fish & 03 & 02 & 03 & S. Enteritidis, Other Salmonella \\
\hline 6 & Milk & 02 & 02 & 02 & S. Dublin \\
\hline & Total & $\mathbf{5 9}$ & $\mathbf{5 8}$ & $\mathbf{5 9}$ & $\begin{array}{l}\mathbf{2 2} \text { S. Dublin, 13 S. typhimurium, } \\
\mathbf{1 2} \text { S. Enteritidis and 12 Other Salmonella }\end{array}$ \\
\hline
\end{tabular}

Figure.1 (A) Turbidity due to formation of magnesium pyrophosphate

Tube 1-No turbidity Tube 2- Turbidity

(B) Addition of SYBR green dye

Tube 1- No fluorescence indicating no DNA amplification

Tube 2-SYBR green fluorescence indicating DNA amplification

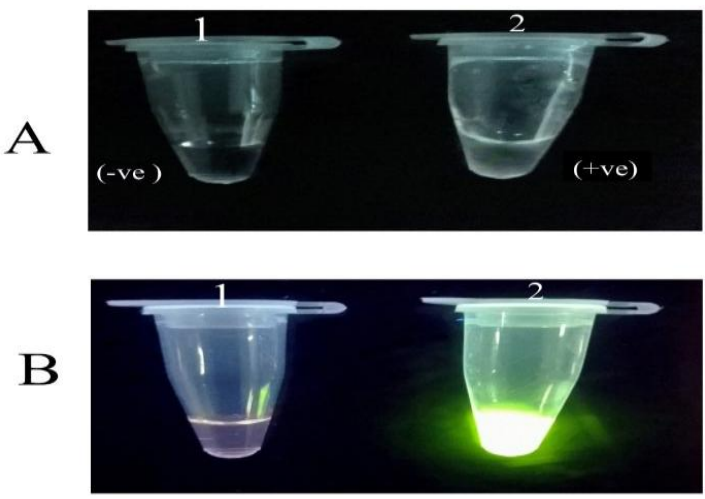


Figure.1 (C) Ladder like pattern of LAMP products

Lane 1-3: Ladder like pattern of LAMP products of Salmonella;

Lane 4: Negative control; Lane M: Marker

(D) Standardization of PCR for invA gene of Salmonella spp.

Lane 1-3: PCR products of Salmonella, spp. Lane M: Marker
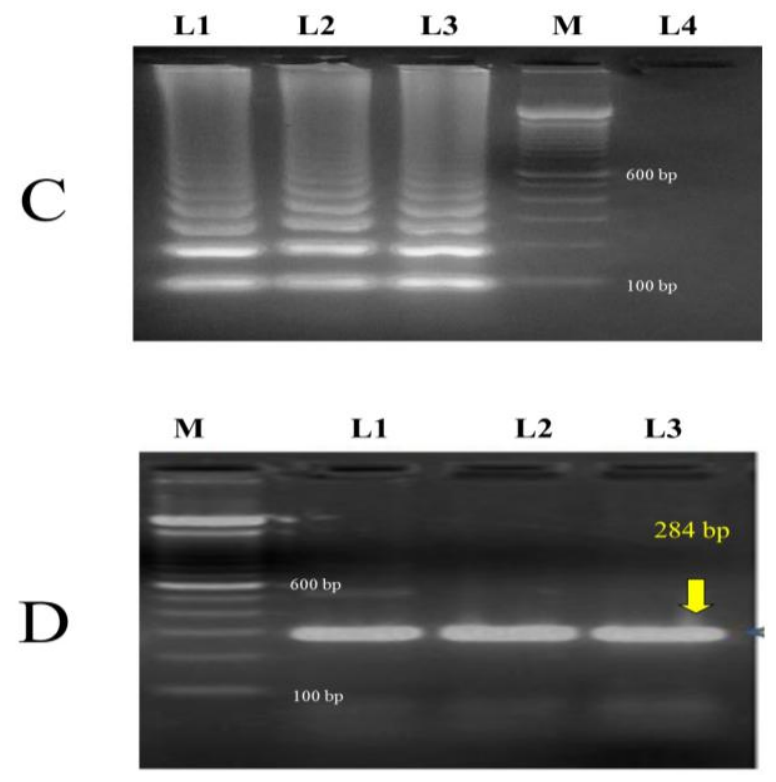

Figure 2: (A) Sensitivity of LAMP assay by addition of SYBR green dye;

Tube 1-3: 400, 40 and 4 ng and in Tube 4-6: 400, 40 and

4 pg per tube of DNA

(B) Ladder like Pattern of LAMP products at different concentrations of DNA

(C) Sensitivity of PCR; Lane 1-3: PCR reactions at 400, 40, 4 ng and in Lane 4-6: 400, 40 and 4 pg per tube of DNA, Lane M:100bp DNA Ladder

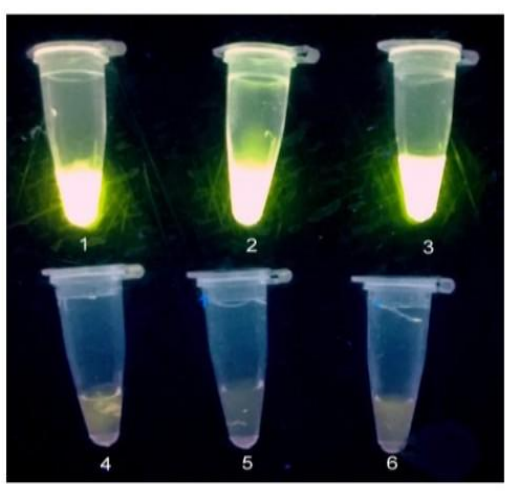

A

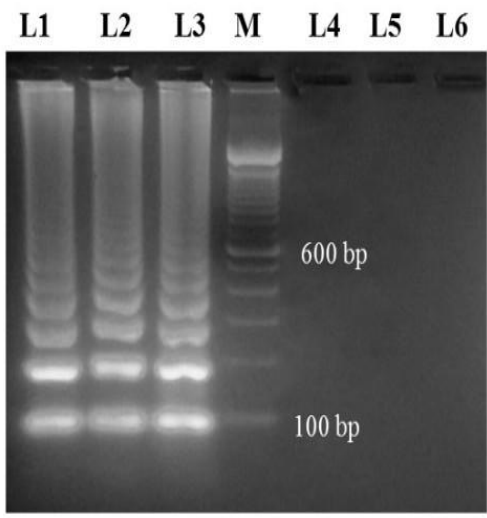

B

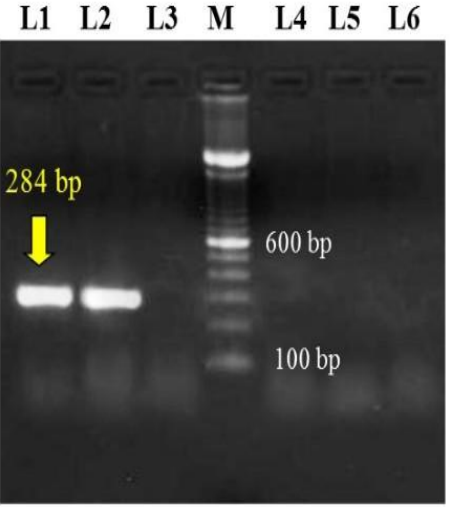

C 
Figure.3(A) Specificity of LAMP assay for Salmonella spp.; Tube 1-4: No any green Fluorescence observed for E. coli, P. aeruginosa, Shigella flexneri and S. aureus. Tube 5: Green fluorescence for Salmonella spp. (B) Specificity of PCR for Salmonella spp. Lane 1-4: No DNA amplification Observed for E. coli, P. aeruginosa, Shigella flexneri and S. aureus Tube 5: DNA amplification for Salmonella spp.; Lane M:100bp DNA Ladder

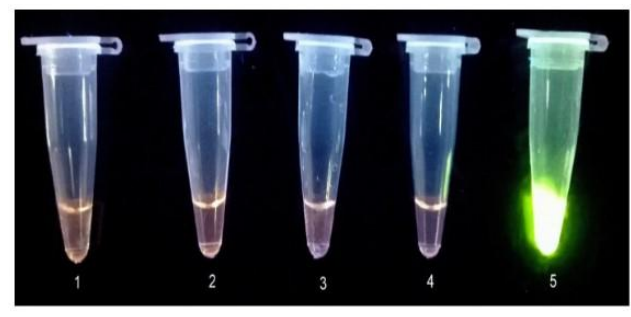

A

In the present study, an in-house LAMP method was developed and successfully applied it to detect Salmonella spp. in foods of animal origin. The target gene invA contains sequences unique to this genus Salmonella and encodes a protein in the inner membrane of bacteria which is responsible for invasion to the epithelial cells of the host (Darwin and Miller, 1999).

All of the 59 isolates of Salmonella spp. recovered from foods of animal origin were found positive (100\%) using LAMP technique. The similar findings were also reported by Hara-Kudo et al., (2005) who could detect all the 220 strains of Salmonella spp. (100\%) using LAMP technique. However, Zhang et al., (2012) detected only $93.55 \%$ (29 of 31) positive Salmonella isolates analyzed by LAMP. This may be attributed to variations in the reaction mixture and primers used lowering the sensitivity of detection.

Compared with PCR could detect $98.30 \%$ (58 out of 59) while LAMP could detect 100\% (59 out of 59) of Salmonella isolates. This may be attributed to the presence of four specific primers targeting six distinct sites on the inv A gene. However, Ohtsuka et al., (2005) and Tang et al., (2012) reported $90 \%$ and $72.72 \%$ detection of positive Salmonella isolates by PCR, respectively, while LAMP technique successfully identified all the Salmonella spp. analyzed (100\%). The sensitivity (detection

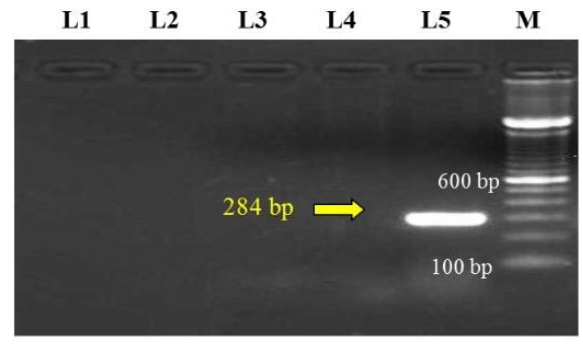

B

limit) of the LAMP assay was noted to be 10 fold greater than that of conventional PCR as LAMP could detect $4 \mathrm{ng} /$ tube of Salmonella spp. DNA concentration, whereas, conventional PCR could able to detect 40ng/tube of concentration of Salmonella spp. DNA.

The results are in accordance with a study conducted by Ueda et al., (2009) using LAMP assay for detection of Salmonella spp. in food and human samples who reported that the LAMP could detect $10^{2} \mathrm{CFU} / \mathrm{ml}$ whereas, the PCR could detect $10^{3}-10^{5}$ CFU $/ \mathrm{ml}$ of Salmonella spp. indicating that LAMP was 10 times more sensitive than PCR in their experiment. The findings are similar with Tang et al., (2012), Zhang et al., (2012) and Wang and Wang et al., (2013) who reported the sensitivity of LAMP assay 10 times higher than the PCR-based method. The results are also in accordance with Abdullah et al., (2014) who reported that LAMP method was highly specific and 10 times more sensitive in detecting S. typhi as compared to the optimized conventional PCR method. However, Pavan Kumar et al., (2014) reported that the LAMP test developed for $S$. typhimurium was 100 times more sensitive than conventional PCR. Similarly, Chan et al., (2015) studied detection limit for LAMP assay for Salmonella spp. was $10^{1} \mathrm{CFU} / \mathrm{ml}$ whereas, PCR could detect $10^{3} \mathrm{CFU} / \mathrm{ml}$ of Salmonella spp. by targeting InvE gene. This variation may be attributed to the difference in LAMP 
conditions and due to species level LAMP for Salmonella spp. carried out in their study.

In the current study the specificity of both LAMP and conventional PCR was found to be $100 \%$. The findings in the present study are similar with the studies carried out by HaraKudo et al., (2005), Ueda et al., (2009), Zhao et al., (2010) and Chan et al., (2015) who reported the specificity of LAMP was equally significant as that of PCR assay i.e. $100 \%$. The specificity results $(100 \%)$ observed in present study are also in accordance with Zhuang et al., (2014) who reported that LAMP technique could amplify all the 44 Salmonella strains successfully, but none of 9 non-Salmonella standard strains used under study.

The study also revealed that LAMP could differentiate and specifically detect only Salmonella spp. from other 4 non-Salmonella strains. However, both LAMP and PCR assays were successfully able to identify only Salmonella spp. without giving any false positive results for non- Salmonella strains showing $100 \%$ specificity for both the assays.

In conclusions Salmonella spp. is one of the major food-borne pathogen that causes outbreak of food-borne disease around the world. Salmonellosis is endemic in India and thus, there is need to develop a rapid, sensitive and specific test for its detection. Therefore, the inhouse developed LAMP assay has higher sensitivity compared to PCR. Moreover, this LAMP assay can further increase the scanning speed and save more time. From a practical point of view, this in-house developed LAMP is a suitable, cost effective method for resourcelimited laboratories and in field applications.

\section{Acknowledgements}

This work was supported by grants from Indian Council of Agricultural Research under the Project All India Co-Ordinated Research Project on Post Harvest Engineering and Technology implemented at Bombay Veterinary College, Mumbai centre

\section{References}

Abdullah, J., Saffie, N., Sjasri, FAR., Husin, A., Abdul-Rahman, Z., Ismail, A., Aziah, I., Mohamed, M. 2014. Rapid detection of Salmonella Typhi by loop-mediated isothermal amplification (LAMP) method. Brazilian J. of Microbiol, 45(4) 13851391

Bacteriological Analytical Manual 2007. BAM: Salmonella, Chapter 5 Salmonella. http://www.fda.gov/ downloads/Food/FoodScienceResearch/U CM309839.pdf acessed on 21 December 2015.

Boehme, C.C., Nabeta, P., Henostroza, G., Raqib, R., Rahim, Z., Gerhardt, M., Sanga, E., Hoelscher, M. 2007.Operational feasibility of using loop-mediated isothermal amplification for diagnosis of pulmonary tuberculosis in microscopy centers of developing countries. J Clin Microbiol 45: 1936-1940.

Chen, Z., Zhang, Ke., Yin, H., Lan, WQL., Liu, Z. 2015. Detection of Salmonella and several common Salmonella serotypes in food by loop-mediated isothermal amplification method. Food Science and Human Wellness 4:75-79

Darwin, K.H. and Miller, V.L. 1999. Molecular basis of the interaction of Salmonella with the intestinal mucosa. Clin. Microbiol. Rev. 12: 405-428.

European Food Safety Authority (EFSA) 2007. The community summary report on trends and sources of zoonoses, zoonotic agents, antimicrobial resistance and foodborne outbreaks in the European Union in 2006. EFSA J. 130: 1-352.

Gould, L.H., Walsh, K.A., Vieira, A.R., Herman, K., Williams, I.T., Hall, AJ. and Cole, D. 2013. Surveillance for foodborne disease outbreaks -United States, 1998-2008. MMWR, 62 (2).

Hara-Kudo, Y., Yoshino, M., Kojima, T. and Ikedo, M. 2005. Loop-mediated Isothermal Amplification for the rapid detection of Salmonella. FEMS Microbiol. Lett. 253(1):155-161.

IS 5887 (1999) Methods for detection of bacteria responsible for food poisoning Part 3: 
General guidance on methods for the detection of Salmonella.

Kokkinos, PA., Ziros, P.G., Bellou, M. and Vantarakis, A. 2014. Loop-Mediated Isothermal Amplification (LAMP) for the Detection of Salmonella in Food. Food Anal. Methods 7:512-526

Kshirsagar, D.P., Singh, S., Brahmbhatt, M.N. and Nayak, J.B. 2014. Isolation and Molecular Characterization of Virulence-Associated Genes of Salmonella from Buffalo Meat Samples in Western Region of India. Israel J. of Vet. Med. 69(4):228-233

Notomi, T., Okayama, H., Masubuchi, H., Yonekawa, T., Watanabe, K., Amino, N., and Hase, T. 2000. Loop-mediated Isothermal Amplification of DNA. Nucleic. Acids. Res. 28(12): 63-66

Ohtsuka, K.K., Yanagawa, K.T. and Hara-Kudo, Y. 2005. Detection of Salmonella enterica in naturally contaminated liquid eggs by Loop-mediated Isothermal Amplification, and characterization of Salmonella isolates. Appl. Environ. Microbiol. 71(11): 6730-6735.

Kumar, P., Agarwal, R.K., Thomas, P., Sailo, B., Prasannavadhana, A., Kumar, A., Kataria, J.L. and Singh, DK. 2014. Rapid Detection of Salmonella enterica subspecies enterica serovar Typhimurium by Loop-mediated Isothermal Amplification (LAMP) test from field chicken meat samples. Food Biotechnol. 28(1): 50-62.

Rahn, K., De Grandis, S.A., Clarke, R.C., McEwen, S.A., Galán, JE., Ginocchio, C., Curtiss, R. and Gyles, C.L. 1992.Amplification of an invA gene sequence of Salmonella Typhimurium by Polymerase Chain Reaction as a specific method of detection of Salmonella. Mol. Cell Probes. 6(4): 271-9.

Tang, T., Cheng, A., Wang, M., Li X, HQ., Jia, R., Zhu, D. and Chen, X. 2012. Development and clinical verification of a Loop-mediated Isothermal Amplification method for detection of Salmonella species in suspect infected ducks. Poultry. Sci. 91: 979-986.

Ueda, S. and Kuwabara, Y. 2009. The rapid detection of Salmonella from food samples by Loop-mediated Isothermal Amplification LAMP. Biocontrol. Sci. 14(2): 73-6.

Wang, Y. and Wang, D. 2013. Development and evaluation of a Loop-mediated Isothermal Amplification (LAMP) method for detecting foodborne Salmonella in raw milk. Advanced Materials. Res.647: 577582.

Yang, J.L., Ma, G.P., Yang, R., Yang, S.Q., Fu, L.Z., Cheng, A.C., Wang, M.S., Zhang, S.H., Shen, K.F., Jia, R.Y., Deng, S.X. and $\mathrm{Xu}, \mathrm{Z} . \mathrm{Y}$. 2010. Simple and rapid detection of Salmonella serovar Enteritidis under field conditions by Loop-mediated Isothermal Amplification. J. App. Microbiol. 109(5): 1715- 1723.

Zhang, L., Pan, Z., Geng, S., Chen, X., Liu, Z., Zhao, F. and Jiao, X. 2012. A Loopmediated Isothermal Amplification method targets the HisJ gene for the detection of foodborne Salmonella. Eur. Food Res. Technol. 234: 1055-1062.

Zhuang, L., Gong, J., Li, Q., Zhu, C., Yu, Y., Dou, X., Liu, X., Xu, B. and Wang, C. 2014. Detection of Salmonella spp. by a Loop-mediated Isothermal Amplification (LAMP) method targeting $b c f D$ gene. Lett. in App. Microbiol. 59: 658-664.

\section{How to cite this article:}

Masoji, V.R., R.J. Zende, R.D. Suryawanshi, V.M. Vaidya, R.N. Waghamare, D.P. Kshirsagar, R.P. Todankar and Shirke, A.H. 2017. Rapid Detection of Salmonella spp. in Animal Origin Foods by InHouse Developed Loop-Mediated Isothermal Amplification (LAMP) Assay. Int.J.Curr.Microbiol.App.Sci. 6(4): 2523-2532. doi: https://doi.org/10.20546/ijcmas.2017.604.294 